\section{Gold mine in East Germany?}

\section{Munich}

BY dumping tonnes of pollutants into the country's air, water and soil without investing a penny in cleaning up, the repressive regime of East Germany created some of the worst environmental conditions in the world. At the same time, the regime was nearly paranoid about keeping its citizens under observation and it maintained meticulous health records, including one of the world's most extensive cancer registries.

Now, in a bizarre twist arising from German unification, these two policies may turn out to provide a basis for epidemiological studies of an unprecedented calibre on the effects of environmental pollution on the incidence of cancer. Epidemiologists from the former West Germany say they are eager to get their hands on the data.

But that may not be as easy as it seems - a number of political, scientific and financial hurdles await the scientists who are hoping to study this potentially invaluable cancer registry.

\section{"Unique opportunity"}

Earlier this month, a western delegation, including epidemiologists, were given a glimpse into the Berlin-based registry. Although the researchers warn that the registry may not be the treasure trove they were hoping for, they remain excited. To western German legal expert Spiros Simitis, a member of the delegation, the mood among the epidemiologists was reminiscent of "prospectors in San Francisco during the gold rush".

One of Germany's leading epidemiologists, Jürgen Wahrendorf of the German Cancer Research Centre in Heidelberg, calls the chance to assess the East German data "a unique opportunity". And Wilhelm Thiele, head of the cancer registry in the western German Land of Hamburg, says "we would be missing an important chance [if we let this drop]". Cancer registries provide just one piece of the puzzle in cancer research and treatment, he notes, but it is an important price.

Between 1953 and 1990, the East German registry collected data on more than 2.1 million cancer cases in a steady population of around 17 million - statistics that make the East German registry the largest in the world in terms of the size of the population it covered.

But if the researchers are to get more than just a glimpse of the East German data, then they must overcome a number of obstacles. The data are now, for instance, recorded on miles of magnetic tape. Simply transferring them to storage accessible to modern computers will certainly be an expensive and labour- intensive task.

Even more daunting will be finding a way to protect the privacy of the subjects of the cancer data, while maintaining free access for researchers. Germany has some of the strictest privacy laws in the world. And it is easy to imagine that eastern Germans, having just been relieved of the secret police called Stasi, may not be eager to have Westerners peering into intimate details of their lives, even if the cause is a good one

One irony of the registry which increases its allure for Western researchers is that it was hardly ever analysed from the point of view of epidemiology - a medical speciality that was not recognized in East Germany. According to registry employee Wolfhard Staneczek, the registry was created at a time when cancer was even more mysterious than it is now, and doctors wanted to know how big a health problem it was. Later, the data were used to estimate the need for hospital beds in different geographical areas.

Partly because the cancer registry was never intended for epidemiologists, it has several shortcomings that may limit its usefulness. For instance, Thiele points out that cancers in some environmentally sensitive areas, such as the region containing the uranium mines in Saxony, may have been excluded from the registry for political reasons - a fact that may drastically reduce the registry's interest for researchers.

Staneczek admits that there were two groups purposely omitted from the registry: uranium miners and "members of the government". (Both Erich Honecker and Walter Ulbricht, heads of state when East Germany was still under Communist rule, are reported to have had cancer.) But these omissions are not statistically significant, he claims.

\section{Erasure is an option}

Epidemiologists may also face legal barriers to the data. Simitis, a professor of law at the University of Frankfurt, says that unless a legal basis can be found for using the registry, the only option will be to "erase all the data". He points out that it would be illegal under German law to grant access to the registry to researchers because the patients whose data are stored there did not give their consent

Creating a legal framework for using the data will be tricky and difficult, not least because of the understandable reluctance of the population to give up privacy in any form to the government.

The reorganization of eastern Germany from its original 229 districts into six Länder (states), including a single Land of Berlin (east and west) will increase the size of the challenge. The transition to a structure based on Länder will also make it more difficult to continue the registry in eastern Germany.

Keeping the registry going, however, would be very desirable, Wahrendorf says, because of the opportunity that it would provide for observing the incidence of cancer in this population in those cases where it may take 10 or 15 more years to emerge.

Legal expert Simitis says that all six Länder must reach an agreement in the form of a treaty to delegate authority over collecting and administering data to one central body. But given the chaotic political conditions that now prevail in eastern Germany, it is unlikely that this will be achieved, says Thiele.

\section{Who will pay}

Under the unification treaty signed last year, Bonn agreed to keep open until the end of 1991 all institutions formerly affiliated with the East German Academy of Sciences. But the Bonn Research and Technology Ministry, which has jurisdiction over the Academy, has said that the eastern German Länder must take over after that.

It is clear that the registry will not be a high enough priority to be maintained by the eastern Länder, all of which are close to bankruptcy. There is a consensus among members of the delegation that the costs for maintaining the registry, or even just for analysing the data already collected, will at least initially have to come from Bonn.

Members of the delegation, which was organized by the science advisory council Wissenschaftsrat, suggested that the campaign to save the registry would gain momentum later this year, when other issues concerning science in eastern Germany have been addressed. The council plans to make a recommendation about the future of the registry by midsummer.

If western German epidemiologists ever do get a good look at the cancer registry, they may be in for a few surprises. Just after unification, the East German registry reported to the Federal Statistics Office in Wiesbaden an unexpected result: despite the obvious additional risk suffered by citizens of East Germany because of environmental pollution, the rate of cancer deaths in 1989 in the east ( 209 per 100,000 population) was actually lower than that in the west (274.5 per 100,000). Staneczek warns that the data must be looked at "extremely sceptically" as the cause of death was determined in a different way in the two German states.

Nevertheless, even these incomplete figures are enough to make western researchers hingry for more.

Steven Dickman 